\title{
Association of petrochemical exposure with spontaneous abortion
}

Xiping Xu, Sung-Il Cho, Mary Sammel, Liangya You, Shangcong Cui, Yinmin Huang, Guohong Ma, Chantana Padungtod, Lucille Pothier, Tianhua Niu, David Christiani, Thomas Smith, Louise Ryan, Lihua Wang

Department of Environmental Health, Harvard School of Public Health, Boston, MA, USA

$\mathrm{XXu}$

S-I Cho

C Padungtod

L Pothier

$\mathrm{T}$ Niu

D Christiani

T Smith

Channing Laboratory, Brigham and Women's Hospital, Harvard Medical School, Boston, MA, USA $\mathrm{X} \mathrm{Xu}$

Beijing Medical University, Center for Eco-Genetics and Reproductive Health, Beijing, China

$\mathrm{XXu}$

Y Huang

L Wang

Department of Biostatistics, Harvard School of Public Health, Boston, MA USA

M Sammel

L Ryan

Yanshan

Anti-epidemic Station, Yanshan, Beijing, China

L You

S Cui

$\mathrm{GMa}$

Massachusetts General Hospital, Harvard Medical School, Boston, MA, USA D Christiani

Dana Farber Cancer Institute, Division of Biostatistics, Boston, MA USA

L Ryan

Correspondence to: Dr Xiping Xu, Department of Environmental Health Harvard School of Public Health, FXB-101, 665 Huntington Avenue, Boston, MA 02115, USA.

Accepted 10 July 1997
Abstract

Objectives-To assess the association between petrochemical exposure and spontaneous abortion, a retrospective epidemiological study in a large petrochemical complex in Beijing, China was conducted.

Methods-Plant employment records identified 3105 women who were married, were 20-44 years of age, and had never smoked. Of those, 3070 women $(98.8 \%)$ reported at least one pregnancy. From this group, 2853 (93\%) of the women participated in the study. According to their plant employment record, about $57 \%$ of these women workers reported occupational exposure to petrochemicals during the first trimester of their pregnancy. Trained interviewers administered a standardised questionnaire to this group of women and their husbands, collecting information on reproductive history, pregnancy outcomes, employment history, occupational exposure, smoking habits, alcohol consumption, indoor air pollution, and demographic variables. The results from the womens' first pregnancies were analysed.

Results-There was a significantly increased risk of spontaneous abortion for women working in all of the production plants with frequent exposure to petrochemicals (8.8\%; range of $5.8 \%-9.8 \%$ ) compared with those working in nonchemical plants $(2.2 \%$; range of $0.0 \%$ $7.1 \%)$. Also, when a comparison was made between exposed and non-exposed groups within each plant, exposure to petrochemicals was consistently associated with an increased risk of spontaneous abortion. The overall odds ratio (OR) was 2.7 (95\% confidence interval $(95 \%$ CI) 1.8 to 3.9) after adjusting for potential confounders. When the analysis was performed with the exposure information obtained from the women' interview responses for (self reported) exposures, the estimated OR for spontaneous abortions was $2.9(95 \%$ CI 2.0 to 4.0$)$. The analysis was repeated by excluding those 452 women who provided inconsistent reports between recalled exposure and work history, and a comparable risk of spontaneous abortion (OR 2.9; 95\% CI 2.0 to 4.4 ) was found. In analyses for exposure to specific chemicals, an increased risk of spontaneous abortion was found with exposure to most chemicals, and the results for benzene (OR 2.5; 95\% CI 1.7 to 3.7 ), gasoline (OR 1.8; 95\% CI 1.1 to 2.9 ), and hydrogen sulphide (OR 2.3; 95\% CI 1.2 to 4.4 ) were significant.

Conclusion-An increased risk of spontaneous abortion was found associated with the exposure to petrochemicals, including benzene, gasoline, and hydrogen sulphide.

(Occup Environ Med 1998;55:31-36)

Keywords: abortion; petrochemical exposure; benzene; gasoline; hydrogen sulphide

It has been suggested that exposure to chemicals arising from petroleum processing is associated with increased frequency of spontaneous abortion. Axelsson and Molin ${ }^{1}$ assessed the pregnancy outcomes in Stenungsund, Sweden, where there were air emissions from petrochemical industries. In general, adverse pregnancy outcomes were not increased in the community. However, they found a significant increase in spontaneous abortions among a group of women who had worked at the petrochemical plant during pregnancy (odds ratio (OR) 6.6; 95\% confidence interval (95\% CI) 2.3 to 19.2). Axelsson and Rylander ${ }^{2}$ conducted a more detailed study among the women workers in one of the petrochemical plants in Stenungsund. They found a significantly higher rate of miscarriage among the women performing laboratory work at the petrochemical plant, contrasted with the expected rate for a comparable non-exposed population in the community. In Bulgaria, Simeonova et al ${ }^{\beta}$ compared the frequency of cytogenetic abnormalities between the workers from the petroleum processing industry and control subjects, stratifying by any previous experience of reproductive failure such as spontaneous abortion, stillbirth, or malformation. The frequency of chromosomal aberrations and sister chromatid exchanges was higher among the group of petroleum processing workers than among the comparison group, and higher among the workers with any history of reproductive failure than among the workers without such history. This result suggests the presence of certain mutagenic substances in the petrochemical processing environment which might have resulted in fetal loss or defect.

To examine the association between exposure to specific petrochemicals and the frequency of fetal loss, we conducted a retrospective study at Beijing Yanshan Petrochemical Corporation (BYPC), a large modern petrochemical plant in Beijing, China in 1993. 
Information on chemical and non-chemical work exposures was obtained from both women workers and their husbands.

\section{Methods}

STUDY SITE

The BYPC, located in a southwest suburb of Beijing, China, has been in operation since 1969. This complex represents a very large integrated set of petroleum and chemical processing operations in 17 different major production plants and institutes. The BYPC currently employs about 47000 workers and staff members, of whom 39539 are production workers (24 490 men and 15049 women). According to the inventory of the complex, 7166 workers have been exposed to petrochemical hazards. Each plant is divided into several subunits, called workshops. Each plant has different workshops. For example, chemical works No 1, one of the major production plants in the complex, has 13 major workshops, covering a range of different types of production: styrene and polystyrene production, ethylene and polyethylene production, benzene and xylene production, and an oil blending unit. As well as production workshops, it also has a quality control laboratory, a waste treatment unit, a maintenance shop, an electronic shop, and other services. Exposure to specific chemicals, including benzene, styrene, toluene, xylene, ethylene, and ethylbenzene, singly, and in combination, varied between the workshops, but the concentrations were generally quite low. The mean concentrations of benzene, toluene, styrene, and xylene for 38 personal samples, collected from five petrochemical plants at BYPC, were 0.86, 0.40, 0.50 , and $0.03 \mathrm{ppm}$, respectively. High exposure in modern petrochemical plants usually occurs during the process of cleaning, repairing, sampling, etc. Although the time weighted average (TWA) was low, the workers may have short term peak exposures which are high and are masked by the TWA averaging.

STUDY POPULATION AND SELECTION

This study was approved by the institutional review boards of Harvard School of Public Health and Beijing Medical University. In the plants, a mandatory system exists for keeping records of female workers' job histories and health information. Based on these plants' health records, we identified 3105 women who currently worked at BYPC, were married to men who worked at BYPC, were between 20 and 44 years of age, and had never smoked. Of those 2853 women, 586 were from the oil refinery, 514 were from chemical plant I, 253 were from the polyester plant, 112 were from the resin plant, 225 were from the carpet plant, and 1163 were from the plants or institutes where petrochemical exposure was much less frequent, including the construction company, machinery plant, transportation company, hospitals, education bureau, BYPC research institute, instrument and meter plant, BYPC schools, BYPC power plant, BYPC overhaul plant, and food industries.
STUDY PROCEDURE

The field survey was conducted between March and October of 1993. Standardised questionnaires, administered by trained interviewers, collected information on reproductive history, pregnancy outcomes, employment history, occupational exposure, smoking habits, alcohol consumption, indoor air pollution, and demographic variables. The survey team comprised locally hired interviewers and a core of permanent staff who moved from site to site. One week was used as a training period for the new interviewers to become accustomed to the questionnaire. An explanatory letter about the study was sent to each of 3105 selected subjects. The BYPC officials and health centres made arrangements for the subjects to participate in the study at centre clinics or hospitals at times that were convenient to them. For those who could not come to the centre, home visits were made. After the 3070 women who had experienced at least one pregnancy were identified and invited to continue to participate (the subset of subjects selected for analysis purposes), 2853 (93\%) women and their husbands responded and provided complete information on reproductive outcomes and exposures. The non-respondents mainly included those who were away during the study period or could not be contacted after three subsequent home visits, and those who refused to participate. The questionnaire responses were reviewed by each field study group leader for completeness and consistency. Missing or ambiguous items were queried during revisits.

ASSESSMENT OF EXPOSURE AND OUTCOME

The assessment of exposure and outcome was determined by interviewing the woman and her spouse. An industrial hygienist familiar with the petrochemical process in the study plants developed a detailed questionnaire to assess current and past exposures, including job title and materials used, type and level of chemicals and dusts to which they were exposed, ventilation, heating, use of personal protective measures, non-chemical exposures including shift work, ergonomic factors, noise, and stress. Degree of each exposure was assessed by the perceived intensity of the exposure. This information was used to calculate exposure during preconception and the first trimester of pregnancy. Exposure during the first, second, and third trimesters was recorded separately for each pregnancy. Also, women were asked to recall their reproductive history, including the number of pregnancies, outcomes of each pregnancy, and contraceptive use before pregnancies. The subjects with exposure to any petrochemicals were classified as exposed.

\section{STATISTICAL ANALYSIS}

All the analyses were restricted to the first pregnancy as most second pregnancies occurred when the first pregnancy resulted in spontaneous abortion, fetal death, or contraceptive failure. Multiple logistic regressions ${ }^{4}$ were used to assess the association between occupational exposure and spontaneous abortion, adjusting for age, educational level, plant, 
shift work, standing and kneeling hours at work, noise level, dust concentration, passive smoking at home and at work, and diet (green vegetables, meat products, and bean products). Perceived exposure to petrochemicals, none or low, middle, or high exposure, were treated as dummy variables in an exposure-response analysis. Also, stratified analyses were conducted to investigate the potential effect modification on associations between petrochemical exposure and spontaneous abortion.

\section{Results}

A total of 2853 women workers had had at least one pregnancy and had complete information on covariates and reproductive outcomes. Of those, 568 reported two pregnancies and 161 reported three or more pregnancies. Again, analyses were restricted to the first pregnancy; the year during which the pregnancies in the analysis occurred ranged from 1973 to 1993 . Fifty four per cent of the pregnancies occurred within the past 10 years. Table 1 shows the sample characteristics. Factors associated with exposure include educational level, shift work, kneeling during work, noise, dust exposure, passive smoking at work, diet (green vegetables, meat products, and bean products), and cold during pregnancy.

Table 2 shows that of the 2853 women analysed, 1620 (57\%) reported exposure to any chemicals during the first trimester of their pregnancy, and 485 (17\%) had exposure to benzene. The overall mean rate of spontaneous abortion for first pregnancies for all of the women in the study $(n=2853)$ was $6.1 \%$. There was an increased risk of spontaneous abortion in each of the plants that used petrochemicals (8.8\%; range of $5.8 \%-9.8 \%$ ), compared with the non-chemical plants $(2.2 \%$; range of $0.0 \%-7.1 \%)$. Women who reported no petrochemical exposure but who worked in plants where chemicals were used had a higher rate of spontaneous abortion $(2.9 \%)$ than those who did not work in a chemical environment $(1.8 \%)$ (table 2). This suggests that there are other risk factors or exposures associated with spontaneous abortions or that exposure is imprecisely measured. Comparison between exposed and non-exposed groups within each plant showed that exposure to petrochemicals was consistently associated with increased risk of spontaneous abortions. After adjustment for potential confounders (including age, educational level, plant, shift work, standing and kneeling hours at work, noise level, dust concentration, passive smoking at home and at work, and diet-green vegetables, meat products and bean productsexposure to petrochemicals was significantly associated with increased risk for spontaneous abortion for the exposed group when compared with the non-exposed group (OR 2.7; $95 \%$ CI 1.8 to 3.9 ).

Because of a relatively large sample size, we were able to identify the top seven frequently exposed chemicals or dusts from collected

Table 1 Sample characteristics of non-smoking and non-drinking female workers (BYPC 1993)

\begin{tabular}{|c|c|c|c|c|c|c|}
\hline \multirow{2}{*}{$\frac{\text { Variable }}{\text { Age at pregnancy }}$} & \multirow{2}{*}{$\begin{array}{l}\text { Status } \\
17-23\end{array}$} & \multicolumn{2}{|c|}{ Exposed } & \multicolumn{2}{|c|}{ Non-exposed } & \multirow{2}{*}{$\frac{P \text { value }}{0.11}$} \\
\hline & & 526 & 32.5 & 355 & 28.8 & \\
\hline & $24-25$ & 715 & 44.1 & 576 & 46.7 & \\
\hline & $\geqslant 26$ & 379 & 23.4 & 302 & 24.5 & \\
\hline \multirow{4}{*}{ Education } & Illiterate or primary & 40 & 2.5 & 55 & 4.5 & 0.002 \\
\hline & Middle school & 510 & 31.5 & 406 & 32.9 & \\
\hline & High school & 892 & 55.0 & 611 & 49.5 & \\
\hline & College and above & 178 & 11.0 & 161 & 13.1 & \\
\hline \multirow{2}{*}{ Shift work } & Day shift & 952 & 58.8 & 1019 & 82.6 & 0.001 \\
\hline & Other shift & 668 & 41.2 & 214 & 17.4 & \\
\hline \multirow[t]{2}{*}{ Standing } & $<3 \mathrm{~h}$ & 1018 & 62.8 & 790 & 64.1 & 0.50 \\
\hline & $>3 \mathrm{~h}$ & 602 & 37.2 & 443 & 35.9 & \\
\hline \multirow[t]{2}{*}{ Kneeling } & None & 1153 & 71.2 & 972 & 78.8 & 0.001 \\
\hline & Any & 467 & 28.8 & 261 & 21.2 & \\
\hline \multirow[t]{2}{*}{ Noise levels } & Quiet & 481 & 29.7 & 684 & 55.5 & 0.001 \\
\hline & Normal or loud & 1139 & 70.3 & 549 & 44.5 & \\
\hline \multirow[t]{2}{*}{ Dust levels } & None & 933 & 57.6 & 1212 & 98.3 & 0.001 \\
\hline & Medium or high & 687 & 42.4 & 21 & 1.7 & \\
\hline \multirow{2}{*}{ Passive smoking at work } & No smokers at work & 1228 & 75.8 & 850 & 68.9 & 0.001 \\
\hline & At least one smoker & 392 & 24.2 & 383 & 31.1 & \\
\hline \multirow[t]{2}{*}{ Passive smoking at home } & No smokers at home & 402 & 24.8 & 337 & 27.3 & 0.13 \\
\hline & At least one smoker & 1218 & 75.2 & 896 & 72.7 & \\
\hline \multirow[t]{2}{*}{ Green vegetables } & $<7$ Servings/week & 1299 & 80.2 & 1032 & 83.7 & 0.02 \\
\hline & $\geqslant 7$ Servings/week & 321 & 19.8 & 201 & 16.3 & \\
\hline \multirow[t]{2}{*}{ Meat products (protein) } & $<3$ Servings/week & 1068 & 65.9 & 761 & 61.7 & 0.02 \\
\hline & $\geqslant 3$ Servings/week & 552 & 34.1 & 472 & 38.3 & \\
\hline \multirow[t]{2}{*}{ Bean products (tofu) } & $<1$ Serving/week & 1049 & 64.7 & 791 & 64.1 & 0.74 \\
\hline & $\geqslant 1$ Serving/week & 571 & 35.3 & 442 & 35.9 & \\
\hline \multirow[t]{2}{*}{ Cold at pregnancy } & None & 1231 & 76.0 & 989 & 80.2 & 0.007 \\
\hline & One or more & 389 & 24.0 & 244 & 19.8 & \\
\hline Total & & 1620 & & 1233 & & \\
\hline
\end{tabular}


Table 2 Number of women workers and spontaneous abortions (SA) by plant and exposure status at BYPC in 1993

\begin{tabular}{|c|c|c|c|c|c|c|c|c|}
\hline Plant & Women (n) & $\begin{array}{l}\text { Total SA } \\
(\%)\end{array}$ & $\begin{array}{l}\text { Women } \\
\text { non-exposed (n) }\end{array}$ & $\begin{array}{l}\text { Non-exposed } \\
S A(\%)\end{array}$ & $\begin{array}{l}\text { Women exposed to } \\
\text { any chemicals }(n)\end{array}$ & $\begin{array}{l}\text { Exposed to any } \\
\text { chemicals } S A(\%)\end{array}$ & $\begin{array}{l}\text { Women exposed } \\
\text { to benzene }(n)\end{array}$ & $\begin{array}{l}\text { Women exposed to } \\
\text { Benzene } S A(\%)\end{array}$ \\
\hline Oil refinery & 586 & $52(8.9)$ & 114 & $7(6.1)$ & 472 & $45(9.5)$ & 185 & $18(9.7)$ \\
\hline Chemical I & 514 & $50(9.7)$ & 185 & $15(8.1)$ & 329 & $35(10.6)$ & 160 & $23(14.4)$ \\
\hline Polyester & 253 & $23(9.1)$ & 88 & $4(4.6)$ & 165 & $19(11.5)$ & 56 & $6(10.7)$ \\
\hline Resin & 112 & $11(9.8)$ & 65 & $6(9.2)$ & 47 & $5(10.6)$ & 13 & $1(7.7)$ \\
\hline Carpet & 225 & $13(5.8)$ & 65 & $3(4.6)$ & 160 & $10(6.3)$ & 45 & $4(8.9)$ \\
\hline Non-chemical & 1163 & $26(2.2)$ & 716 & $13(1.8)$ & 447 & $13(2.9)$ & 26 & $1(3.9)$ \\
\hline Total & 2853 & $175(6.1)$ & 1233 & $48(3.9)$ & 1620 & $127(7.8)$ & 485 & $53(10.9)$ \\
\hline
\end{tabular}

information on job history. These specific chemicals or dusts, in descending order of exposure frequency, are benzene $(17.0 \%)$, gasoline $(8.7 \%)$, acid $(4.0 \%)$, manganese $(3.9 \%)$, lime dust $(3.7 \%)$, hydrogen sulphide (3.7\%), and ammonia (3.4\%). An increased risk of spontaneous abortion was observed with exposure to several chemicals, and the results for benzene, gasoline, and hydrogen sulphide showed a relatively strong association (table 3 ). According to stratified analyses, there was no evidence that the effect of petrochemical exposure on spontaneous abortion was modified by any other factors.

Accurate information is critical in any occupational and environmental epidemiological study. We explored several ways to define and analyse occupational exposures to petrochemicals. A second analysis was performed, with self reported exposure information obtained from women in the first trimester of pregnancy. A significantly lower prevalence of exposure was found from self reports $(43.6 \%$ and $43.2 \%$, respectively) than from job history $(56.8 \%)$. However, the estimated OR of spontaneous abortion with exposure in the first trimester was 2.9 (95\% CI 2.0 to 4.0 ), which is comparable with the ORs based on job history information. A total of 452 women reported their occupational exposure to petrochemicals inconsistently between job history and interview. We repeated the analysis by excluding those 452 women and found a comparable risk of spontaneous abortion (OR 2.9; 95\% CI 2.0 to 4.4). We further analysed the data by restricting the samples to those women who were pregnant during the past 10 years (1984-93) to examine the potential effect of recall bias on the estimates. The estimated OR was 2.9 (95\%

Table 3 Estimated odds ratio of spontaneous abortion with occupational exposure to petrochemicals in women workers at BYPC in 1993

\begin{tabular}{llll}
\hline Exposures & Exposed $(n(\%))$ & $S A(n(\%))$ & OR (95\% CI) \\
\hline Exposure based on interview & $1232(43.2)$ & $111(9.0)$ & $2.9(2.0$ to 4.0$)$ \\
Exposure based on job history & $1620(56.8)$ & $127(7.8)$ & $2.7(1.8$ to 3.9$)$ \\
Consistent exposure & $1200(50.0)^{\star}$ & $110(9.2)$ & $2.9(2.0$ to 4.4$)$ \\
Specific chemicals: & & & \\
$\quad$ Benzene & $485(17.0)$ & $53(10.9)$ & $2.5(1.7$ to 3.7$)$ \\
Gasoline & $247(8.7)$ & $24(9.7)$ & $1.8(1.1$ to 2.9$)$ \\
Acid & $114(4.0)$ & $10(8.8)$ & $1.7(0.8$ to 3.5$)$ \\
Manganese & $112(3.9)$ & $5(4.5)$ & $1.0(0.3$ to 2.7$)$ \\
Lime dust & $105(3.7)$ & $6(5.7)$ & $1.1(0.4$ to 3.1$)$ \\
Hydrogen sulphide & $106(3.7)$ & $13(12.3)$ & $2.3(1.2$ to 4.4$)$ \\
Ammonia & $97(3.4)$ & $8(8.3)$ & $1.2(0.5$ to 2.6$)$ \\
Other hazards & $593(20.8)$ & $36(6.1)$ & $1.6(1.0$ to 2.6$)$ \\
\end{tabular}

* Those with inconsistent exposure information were removed from the analysis.

$\star \star$ Other hazards include: all petrochemical hazards except benzene, gasoline, manganese, acid, lime dust, hydrogen sulphide, and ammonia.

Logistic models include all seven exposures in the same model, as well as age of mother, educational level of mother, shift work, standing at work, kneeling at work, noise levels at work, dust levels at work, passive smoking at work, passive smoking at home, consumption of green vegetables/meat products/bean products, and having a cold at time of conception.
CI 1.8 to 4.6 ), which is identical to that from the total sample.

Finally, an exposure-response trend for increasing risk of spontaneous abortion with increasing exposure to petrochemicals was found, based on the information from interviews with the women on exposure levels during the first trimester of pregnancy. The estimated ORs of associations between middle and high levels of exposure to petrochemicals and spontaneous abortion are 2.7 (95\% CI 1.9 to 3.9$)$ and 3.2 (95\% CI 1.8 to 5.7$)$, respectively, suggesting an exposure-response relation.

\section{Discussion}

The study showed that exposure to petrochemicals, specifically benzene, gasoline, and hydrogen sulphide is significantly associated with increased frequency of spontaneous abortion. Benzene is an important industrial chemical, a petroleum by product, a component of unleaded gasoline and, thus, a ubiquitous environmental pollutant. In 1985, the total United States production of benzene was 9.73 billion tonnes. Animal and in vitro studies have shown that exposure to benzene can cause embryotoxicity and reduced fetal weight..$^{5-8}$ The effects of benzene and some of its metabolites are shown to cross the placenta in pregnant mice and produce considerable toxic effects in fetal liver. ${ }^{9}$ Although the need for study of human reproductive risks from exposure to benzene has been recognised, ${ }^{10}$ few studies have actually focused on reproductive effects of exposure to benzene, and these contain some inconsistencies. Taskinen et $a l^{11}$ found a non-significant excess of spontaneous abortion among pharmaceutical industry workers exposed to benzene. A case-control study in China $^{12}$ found an increased risk of spontaneous abortion (risk ratio 2.4).

Gasoline is a highly variable mixture of volatile hydrocarbons, predominantly in the $\mathrm{C} 4-$ $\mathrm{C} 12$ range, with a boiling range of $50-200^{\circ} \mathrm{C} .{ }^{13}$ There is limited literature on the reproductive toxicity of gasoline. Disturbances in the ovulatory cycle have been reported in women who were occupationally exposed to gasoline vapours. ${ }^{14}{ }^{15}$ Unleaded gasoline is shown to have oestrogenic effects in a study of B6C3F1 mice. ${ }^{16}$ Gasoline exposure among female workers was associated with perinatal mortality ${ }^{17}$ and changes in menstrual cycles. ${ }^{18}$ Hydrogen sulphide gas is a highly toxic irritant and asphyxiant in high doses. ${ }^{19}$ At lower exposures, the reproductive effects of hydrogen sulphide have not been determined, although it has been 
shown to enhance the fetal toxicity of carbon disulphide. ${ }^{20}$

The modern petrochemical industry, including the example in this study, has reached a stage of high automation, and routine chemical exposure is maintained at a very low level. ${ }^{13}$ Therefore, chemical exposures occur mainly in maintenance operations and unscheduled events such as a leak or spillage. Under these circumstances, volatile organic solvents constitute the main components of chemical exposures in petroleum processing. Exposure to various organic solvents has been shown to be associated with spontaneous abortion. In a recent review of epidemiological studies by Lindbohm, ${ }^{21}$ toluene seemed to have the strongest evidence to support the association with spontaneous abortion. In a study among laboratory workers, ${ }^{22}$ use of toluene, xylene, or formalin during the first trimester was significantly associated with an increased risk for spontaneous abortion. Lindbohm et $a l^{23}$ reported a case-control study which showed that aliphatic hydrocarbons are associated with increased spontaneous abortion. In another review of six Finnish studies, ${ }^{24}$ methylene chloride, tetrachloroethylene, and aliphatic hydrocarbons were associated with spontaneous abortion. Most of these organic solvents can be found during petrochemical processing because of the complex composition of petroleum. In the current study, these solvents are likely to result in the increased risk of spontaneous abortion in the "other hazard" category (table 3 ).

There are potential limitations to this study. As a retrospective study which relies on subjects' recall for the assessment of exposure and outcome, recall bias is an important issue as exposure and outcome information is likely to be less reliable for older pregnancies. However, as most subjects had only a few, relatively recent, pregnancies, the subjects' job tasks were fairly constant, and most of the subjects had a high school education, the recall of exposure and pregnancy outcome should be relatively accurate. Also, the results are generally consistent with previous reports. In our data, the frequency of spontaneous abortion among the non-exposed workers is low $(3.9 \%$, table 2). A low spontaneous abortion rate has been found in most of the reproductive health studies in Beijing and in other areas in China. For example, we have carried out another independent study in Wuhu, Anhui Province, China (east part of China) with the same questionnaire and sampling method. The spontaneous abortion rate was $2.8 \%$ in non-exposed women workers (unpublished data), which is comparable with that in Beijing. Although a recall bias cannot be completely excluded in any retrospective study, several factors may be attributed to the low rate of spontaneous abortion. Firstly, most of the Chinese women in the study are non-smokers and non-alcohol drinkers. Secondly, most of the women had their first pregnancies between the ages of 20 and 30 years. Finally, an effective family planning system and premarital healthcare system have been established and implemented to encour- age use of contraception when a woman has any medical condition associated with a high risk of reproductive failure.

We were concerned with various potential confounders, including other exposures in the workplace as well as lifestyle factors such as diet and smoking. Considering the complexity of exposures in petroleum processing, we concentrated our efforts particularly on measurement of a wide range of potential workplace exposures including 40 major potential chemical exposures based on subjects' knowledge as well as on the work process in the plant. For many of the chemicals, the prevalence of exposure was low $(<3 \%)$. We included the seven most prevalent chemical exposures in our multivariate model to control confounding. Finally, selection bias should be minimal because most of the eligible subjects participated in the study.

Strengths of this study included large sample size, detailed exposure information obtained for both women and men, consideration of multiple confounders, and uniform samplefor example, to first pregnancies among non-smokers. We corroborated an association of petrochemical exposure and increased frequency of spontaneous abortion, of which major components of the exposure seemed to be benzene, gasoline, and hydrogen sulphide. A male mediated pathway to this association did not seem to be important, although it could not be confidently ruled out.

The results of this study suggest the need for further research. Quantitative chemical measurement of the exposures among female and male subjects would help to refine the exposure-response relation and minimise confounding. Identifying subclinical spontaneous abortion by assessment of $\beta$-human chorionic gonadotrophin ( $\beta$-hCG) would avoid potential bias and give more power to the study. These improvements can be done efficiently only in a prospective cohort study of petrochemical workers.

This work was supported by NIEHS grant ES00002, NIOSH grant R01 OH03027, NICHD grant, R01HD32505, NIEHS grant 1 R01 ES 08337, and March of Dimes grant 6-FY95-0235.

1 Axelsson G, Molin I. Outcome of pregnancy among women living near petrochemical industries in Sweden. Int f Epidemiol 1988;17:363-9.

2 Axelsson G, Rylander R. Outcome of pregnancy in women engaged in laboratory work at a petrochemical plant. $A m \mathcal{F}$ Ind Med 1989;16:539-45.

3 Simeonova M, Georgieva V, Alexiev C. Cytogenetic investiSimeonova $M$, Georgieva V, Alexiev C. Cytogenetic investi-
gations of human subjects occupationally exposed to gations of human subjects occupationally exposed to
chemicals from the petroleum-processing industry. Environ Res 1989;48:145-53.

4 Hosmer DW, Lemeshow S. Applied logistic regression. New York: John Wiley, 1989.

5 Schwetz BA. A review of the developmental toxicity of benzene. In: Mehlman MA, ed. Carcinogenecity and toxicity of benzene. New Jersey: Princeton Scientific Publishers, 1983: $17-21$.

6 Ungvary G, Tatrai E. On the embryotoxic effects of benzene and its alkyl derivatives in mice, rats and rabbits. Arch Toxicol Supp 1985;8:425-30.

7 Sharma RK, Jacobson-Kram D, Lemmon M, Bakke J, Galperin I, Blazak WF. Sister-chromatid exchange and cell replication kinetics in fetal and maternal cells after treatment with chemical teratogens. Mutat Res 1985;158: 217-31.

8 Maronpot RR. Ovarian toxicity and carcinogenicity in eight recent national toxicology program studies. Environ Health Perspect 1987;73:125-30.

9 Ciranni R, Barale R, Marrazzini A, Loprieno N. Benzene and the genotoxicity of its metabolites. Mutat Res 1988;208:61-7. 
10 Davis DL, Pope AM. Reproductive risks of benzene: need for additional study. Toxicol Ind Health 1986;2:445-51.

11 Taskinen HK, Lindbohm M-L, Hemminki K. Spontaneous abortions among women working in the pharmaceutical industry. Br f Ind Med 1986;43:199-205.

12 Huang XY. Influence on benzene and toluene to reproductive function of female workers in leather shoe-making industry. Chinese Fournal of Preventive Medicine 1991;25: $89-91$.

13 International Agency for Research on Cancer. Occupational exposures in petroleum refining: crude oil and major petroleum fuels. Lyon: IARC, 1989.

14 Mirinski V, Spanov S. Effect of gasoline vapors on the hormonal activity of the ovaries. Akusherstuo $i$ Ginekologia 1979;18:430-2.

15 Feller I. Materials for evaluating the gonadotrophic and mutagenic action of grade BP-1 gasoline. Gigiena Trwda $i$ Professional nye Zabolevaniia 1972;16:25-8.

16 Standeven AM, Wolf DC, Goldworthy TL. Interactive effects of unleaded gasoline and estrogen on liver tumor promotion in female B6C3F1 mice. Cancer Res 1994;54: 1198-204.

17 Mukkametova GM, Vozovaya MA. Reproductive power and incidence of gynecological affections among female workers exposed to a combined effect of gasoline and chlorinated hydrocarbons. Gigiena Trwda i Professional nye Zabolevaniia 1972;16:6-9.

18 Ponova Z. Menstrual and reproductive function and gynecological morbidity in women in occupational contact with gasoline. Letopisi Na Higienno-Epidemiologic Nata Slugba 1976;20:53-6.

19 Beauchamp Jr RO, Bus JS, Popp JA, Boreiko C, J, Andjelkovich DA. A critical review of the literature on hydrogen sulfide toxicity. CRC Crit Rev Toxicol 1984;13:25-97.

20 Saillenfait AM, Bonnet P, de Ceaurriz J. Effects of inhalation exposure to carbon disulfide and its combination with hydrogen sulfide on embryonal and fetal development in rats. Toxicol Lett 1989;48:57-66.

$21 \mathrm{Lindbohm} \mathrm{M-L.} \mathrm{Effects} \mathrm{of} \mathrm{parental} \mathrm{exposure} \mathrm{to} \mathrm{solvents} \mathrm{on}$ pregnancy outcome. 7 Occup Environ Med 1995;37:908-14.

2 Taskinen HK, Kyyronen P, Hemminki K, Hoikkala M, Lajunen $\mathrm{K}$, Lindbohm M-L. Laboratory work and pregnancy outcome. F Occup Med 1994;36:311-9.

23 Lindbohm M-L, Taskinen H, Sallmen M, Hemminki K. Spontaneous abortions among women exposed to organic Spontaneous abortions among women

24 Lindbohm M-L, Taskinen H, Kyyronen P, Sallmen M, Anttila A, Hemminki K. Effects of parental occupational exposure to solvents and lead on spontaneous abortion. Scand $\mathcal{f}$ Work Environ Health 1992;18(suppl 2):37-9.

\section{Rejected manuscripts}

From February 1994, authors whose submitted articles are rejected will be advised of the decision and one copy of the article, together with any reviewer's comments, will be returned to them. The fournal will destroy remaining copies of the article but correspondence and reviewers' comments will be kept. 